\title{
Burning mouth syndrome and other oral sensory disorders: A unifying hypothesis
}

\author{
Miriam Grushka MSc DDS PhD ${ }^{1}$, Joel B Epstein DMD MSD FRCDC ${ }^{2}$, Meir Gorsky DMD ${ }^{3}$
}

\begin{abstract}
M Grushka, JB Epstein, M Gorsky. Burning mouth syndrome and other oral sensory disorders: A unifying hypothesis. Pain Res Manage 2003;8(3):133-135.

Burning Mouth Syndrome (BMS) is a sensory disorder which results in constant, bilateral burning pain of the tongue, lips, and other oral mucous membranes. Atypical odontalgia $(\mathrm{AO})$ is another sensory disorder, usually defined as a toothache-like pain for which no dental cause can be identified. Previous literature has suggested that AO is often associated with a concomitant temporomandibular disorder (TMD). This hypothesis paper explores the possibility that BMS, AO and TMD can be related through hyperactivity of both the sensory and motor components of the trigeminal nerve following loss of central inhibition as a result of taste damage in the chorda tympani and/or the glossopharyngeal nerves.
\end{abstract}

Key Words: Atypical odontalgia; Burning Mouth Syndrome; Temporomandibular disorder

Burning mouth syndrome (BMS) is a sensory disorder result$\mathrm{B}_{\text {ing in constant, often bilateral, burning pain in the tongue, }}$ lips and other oral mucous membranes of an individual without clinical signs of any pathology and no relevant laboratory findings (1). Although more than one oral site is often affected, the anterior tongue, hard palate and the lower lip are most often involved. The pain usually remits during sleep and returns in the morning, progressively increasing over the day and reaching maximum intensity by late afternoon. The pain is frequently relieved by eating. An increased prevalence of personality disturbances have been found in some BMS patients, with a positive correlation with reported pain intensity levels.

Several potential causes of BMS have been considered but none of these are consistently demonstrated in affected individuals. Recent research suggests that conditions such as BMS may be linked to other orofacial pain such as atypical odontalgia $(\mathrm{AO})$ and other sensory dysesthesias (2-4), suggesting the possibility that peripheral oral changes may lead to the emergence of neuropathic-like pain conditions through a common mechanism. We present a hypothesis that links BMS to altered taste and propose that the common pathway of BMS and possibly other oral dysesthesias may be mediated through the taste system.

\section{Brûlures de bouche et autres troubles sen- soriels buccaux : hypothèse unificatrice}

Les brûlures de bouche sont un trouble sensoriel qui se manifeste par une sensation constante de brûlure de chaque côté de la langue, des lèvres et d'autres membranes muqueuses de la bouche. L'odontalgie atypique est un autre trouble sensoriel généralement défini comme un mal de dent ayant une origine non dentaire. D'après la documentation, l'odontalgie serait souvent associée à des troubles temporomandibulaires (TTM) concomitants. Le présent article explore l'hypothèse selon laquelle les brûlures de bouche, l'odontalgie et les TTM puissent tous résulter de l'hyperactivité des fibres motrices et sensitives du trijumeau par suite de la perte de l'inhibition centrale causée par des lésions des centres gustatifs se trouvant dans la corde du tympan ou les nerfs glosso-pharyngiens.

\footnotetext{
${ }^{1}$ Department of Oral Medicine and Diagnostic Sciences, University of Illinois, Chicago, Illinois, USA, and William Osler Health Centre, Etobicoke Campus, Toronto, Ontario; ${ }^{2}$ Department of Oral Medicine and Diagnostic Sciences, University of Illinois, Chicago, Illinois, USA, and Vancouver Hospital and Health Sciences Centre, Vancouver, British Columbia; ${ }^{3}$ Department of Oral Pathology and Oral Medicine, The Maurice and Gabriella Goldschleger School of Dental Medicine, Tel Aviv University, Tel Aviv, Israel

Correspondence: Dr Joel Epstein, Department of Oral Medicine and Diagnostic Sciences MC 838, College of Dentistry, University of Illinois 801 South Paulina Street, Chicago, Illinois 60612, USA. Telephone 312-996-7480, fax 312-355-5667, e-mail mgrushka@uic.edu
} 
studies have not supported irritation from dentures, allergic reaction to dental materials or galvanic currents between dissimilar metals in the mouth.

A series of case reports have demonstrated mouth burning and taste loss secondary to the use of angiotensin converting enzyme inhibitors such as captopril, enalapril and lisinopril (6). In these cases, once these medications are reduced or discontinued, the burning may remit within several weeks.

Taste changes have been reported in two-thirds of BMS patients and include distortion of normal taste perception during eating and/or persistent dysgeusic, or phantom bitter or metallic tastes (5-7). Of note, these dysgeusic tastes often decrease in intensity, as does the oral burning pain for the duration of eating (5) but return immediately thereafter. The link between taste and pain is further supported by the recent finding that low dose clonazepam in up to two-thirds of BMS patients and patients with altered taste sensation can be effective in reducing both oral burning pain and accompanying taste disturbances (8).

Dry mouth has also been reported in BMS (5), although normal salivary flow rates may be present (6). Alterations in salivary constituents including levels of proteins, mucin, selective immunoglobulins, phosphates, $\mathrm{pH}$ and buffering capacity have been reported. Although the relationship of these alterations in salivary composition to BMS is unknown, these changes are suggestive of an alteration in autonomic function (9) that could be linked to distortions of the taste sensation and loss of central inhibition in the trigeminal system $(10,11)$.

In patients with BMS, taste alterations, especially to bitter stimuli in areas of the tongue innervated by the chorda tympani and the glossopharyngeal nerves, have been reported $(12,13)$. Selective damage to the sensation of taste may result in a central loss of inhibition to pain, and may cause spontaneous taste and pain 'phantoms' resulting in BMS. This damage may be caused by viral insult, medication or loss of estrogen at the time of menopause, which is known to significantly affect the ability to taste bitter substances at the chorda tympani $(10,12,13)$. Hormone replacement therapy after the onset of BMS may be ineffective in reducing symptoms once damage to bitter taste areas of the tongue has occurred (9).

The pain intensity of BMS has been shown to correlate with the density of fungiform papillae on the tip of the tongue and most BMS patients have been found to be 'supertaster' individuals with a high density of fungiform papillae (13). Since each taste bud is surrounded by pain fibres, those with the highest number of taste buds may also have the highest density of pain innervation and appear to consequently be at highest risk at developing abnormalities of taste and oral pain.

Oral pain, including BMS, may arise as a result of a central loss of pain inhibition following the selective taste changes outlined above. Also, most BMS patients experience an increase in burning pain following an oral anesthetic rinse, suggesting that the loss of inhibition results in BMS and taste abnormalities (14).

This model, if borne out by further experimental evidence, may explain why postmenopausal women, especially supertasters (13), are at a greatest risk of developing phantom oral sensations, such as BMS.

\section{BURNING MOUTH SYNDROME, ATYPICAL ODONTALGIA AND TEMPOROMANDIBULAR DISORDER}

$\mathrm{AO}$ is defined as toothache-like (aching) pain for which no dental cause can be found. Recent findings also suggest that supertasters are at an increased risk of developing $\mathrm{AO}(4,15-17)$. Some patients with $\mathrm{AO}$ also complain of burning mouth pain and taste disturbances (17), suggesting a possible association of pain and taste in oral pain disorders other than BMS. In addition, this association suggests the possibility that these two apparently diverse disorders may be linked through taste changes and subsequent trigeminal loss of inhibition. Additional support for the link between oral burning and taste is suggested by retrospective studies of inferior alveolar and lingual nerve injuries following local anaesthesia, which in some patients may cause taste loss or taste change as well as burning pain following injury (18).

In addition to the linkage of $\mathrm{AO}$ to $\mathrm{BMS}, \mathrm{AO}$ has been reported in patients with temporomandibular disorder (TMD) (15). It is possible that loss or alteration of taste in the chorda tympani and/or glossopharyngeal nerves may result in a central loss of inhibition of the trigeminal nerve with subsequent hyperactivity of both the sensory and motor function, which may result in increased activity in the muscles of mastication and the intrinsic muscles of the tongue. Because $\mathrm{AO}$ may also involve the sympathetic nervous system (15), it is possible that alterations in taste may also lead to alterations in autonomic output to the salivary glands and result in the sensation of mouth dryness and the qualitative changes to saliva documented in some cases of BMS (6).

Similar medications may be prescribed $(1,5,9)$ for many of the oral sensory disturbances and TMD, including low dose clonazepam and the same types of anticonvulsant medications (eg, gabapentin, topiramate) used to treat trigeminal neuralgia $(18,19)$. Other treatments are similar to those used for other neuropathic pain conditions (20) including tricyclic antidepressants $(1,9)$. There is limited support for topical capsaicin as a desensitizing agent (21) in BMS and in AO (19). In many patients with all of these conditions, a multidisciplinary approach, sometimes associated with polypharmacy, may be required.

\section{REFERENCES}

1. Grushka M, Epstein JB, Kawalec JS. Burning Mouth Syndrome. In: Silverman S Jr, Eversole LR, Truelove EL, eds. Evolving Concepts of Burning Mouth Syndrome, Essentials of Oral Medicine. Hamilton: BC Decker Inc, 2001:354-8.

2. Dubner R, Gold M. The neurobiology of pain. Proc Natl Acad Sci USA 1999;96:7627-30.

3. Woda A, Pionchon P. A unified concept of idiopathic orofacial pain: Pathophysiologic features. J Orofac Pain 2000;14:196-212.

4. Okeson JP, ed. Orofacial Pain: Guidelines for Assessment, Diagnosis, and Management. The American Academy of Orofacial Pain. Illinois: Quintessence Publishing Co, 1991.

5. Grushka M. Clinical features of burning mouth syndrome. Oral Surg Oral Med Oral Path. 1986;63:30-6.

6. Grushka M, Kawalec J, Epstein JB. Burning mouth syndrome: Evolving concepts. Oral Maxillofac Surg Clin North Am 2000;12:287-95.

7. Formaker BK, Frank ME. Taste function in patients with oral burning. Chem Senses 2000;25:575-81.

8. Grushka M, Epstein J. An open label dose escalation pilot study of the effect of clonazepam in gurning mouth syndrome. Oral Surg Oral Med Oral Pathol Radiol Endod 1998;86:557-61. 
9. Grushka M, Epstein JB, Gorsky M. Burning mouth syndrome: A Challenging medical dilemma. J Am Fam Phys 2002;65:615-20.

10. Bartoshuk LM, Caseria D, Catalanotto F, et al. Do taste-trigeminal interactions play role in oral pain? Chem Senses 1996;21:578.

11. Brown JA. The trigeminal complex. Neurosurg Clin North Am 1997;8:1-8.

12. Bartoshuk L, Kveton J, Yanagisawa K, Catalanotto F. Taste loss and taste phantoms: A role of inhibition in the taste system.

In: Kurihara K, Suzuki N, Ogawa H, eds. Olfaction and Taste XI. Tokyo: Springer-Verlag, 1994:557-60.

13. Grushka M, Bartoshuk L. Burning mouth syndrome and oral dysesthesias: Taste injury is a piece of the puzzle. Can J Diagnosis 2000;17:99-109.

14. Formaker BK, Mott AE, Frank ME. The Effects of topical anesthesia on oral burning in burning mouth syndrome. Annals NY Acad Sci 1998;885:776-801.

15. Vickers ER, Cousins MJ, Walker S, Chisholm K. Analysis of 50 patients with atypical odontalgia. Oral Surg Oral Med Oral Pathol
Oral Radiol Endod 1998;85:24-32.

16. Marbach JJ. Is phantom tooth pain a deafferentation (neuropathic) syndrome? Part II: Psychosocial considerations. Oral Sug Oral Med Oral Pathol 1993;75:225-32

17. Grushka M, Bartoshuk L. Atypical odontalgia: Evidence for involvement of the chorda tympani. Oral Surg Oral Med Oral Pathol Oral Radiol Endod 2001;91:414.

18. Haas DA, Lennon D. A 21 year retrospective study of reports of paresthesia following local anesthetic administration. J Can Dent Assoc 1995;61:319-30.

19. Turp JC, Gobetti JP. Trigeminal neuralgia versus atypical facial pain. Oral Surg Oral Med Oral Pathol Oral Radiol Endod 1996;81:424-32.

20. Sirois DA. Orofacial neuralgias and neuropathic pain. In: Silverman S Jr, Eversole, LR, Truelove EL, eds. Essentials of Oral Medicine. Hamilton: BC Decker Inc, 2001;339-53.

21. Epstein JB, Marcoe JH. Topical application of capsaicin for treatment of oral neuropathic pain and trigeminal neuralgia. Oral Surg Oral Med Oral Pathol Oral Radiol 1994;77:135-40. 


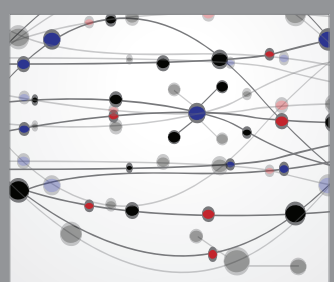

The Scientific World Journal
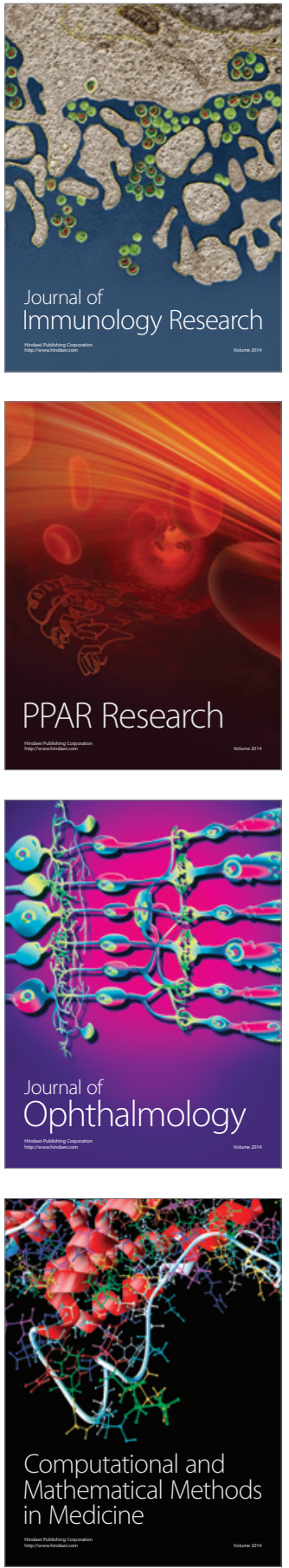

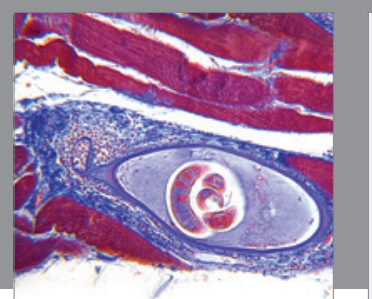

Gastroenterology Research and Practice

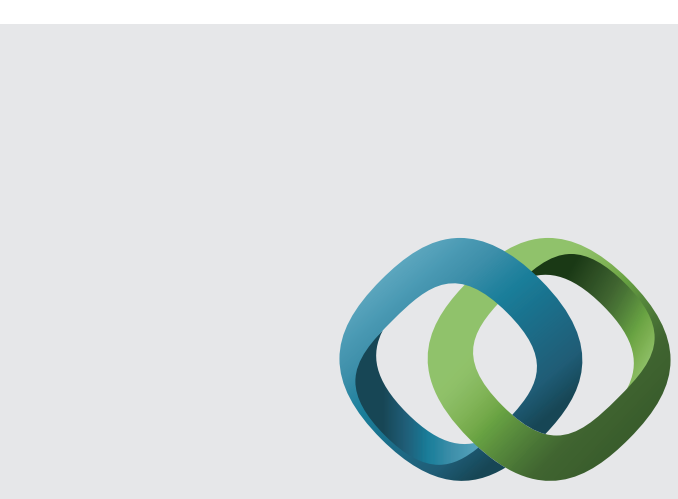

\section{Hindawi}

Submit your manuscripts at

http://www.hindawi.com
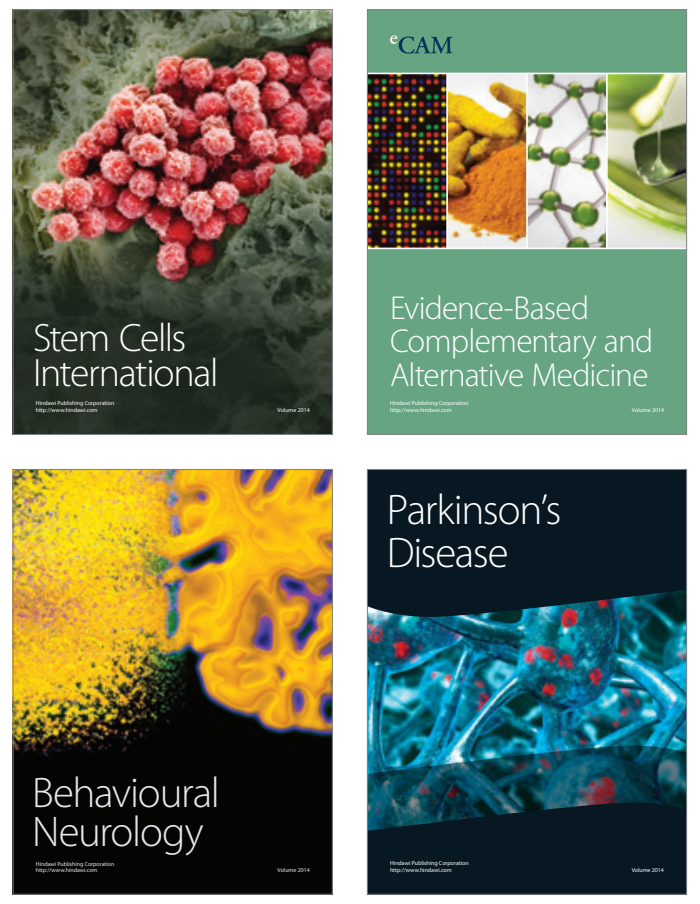
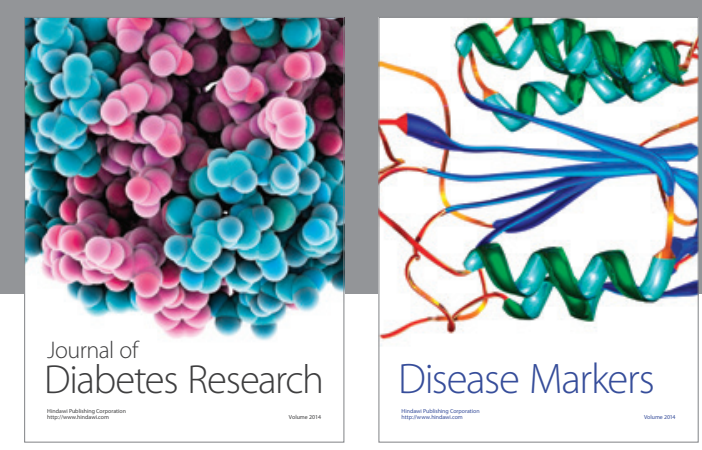

Disease Markers
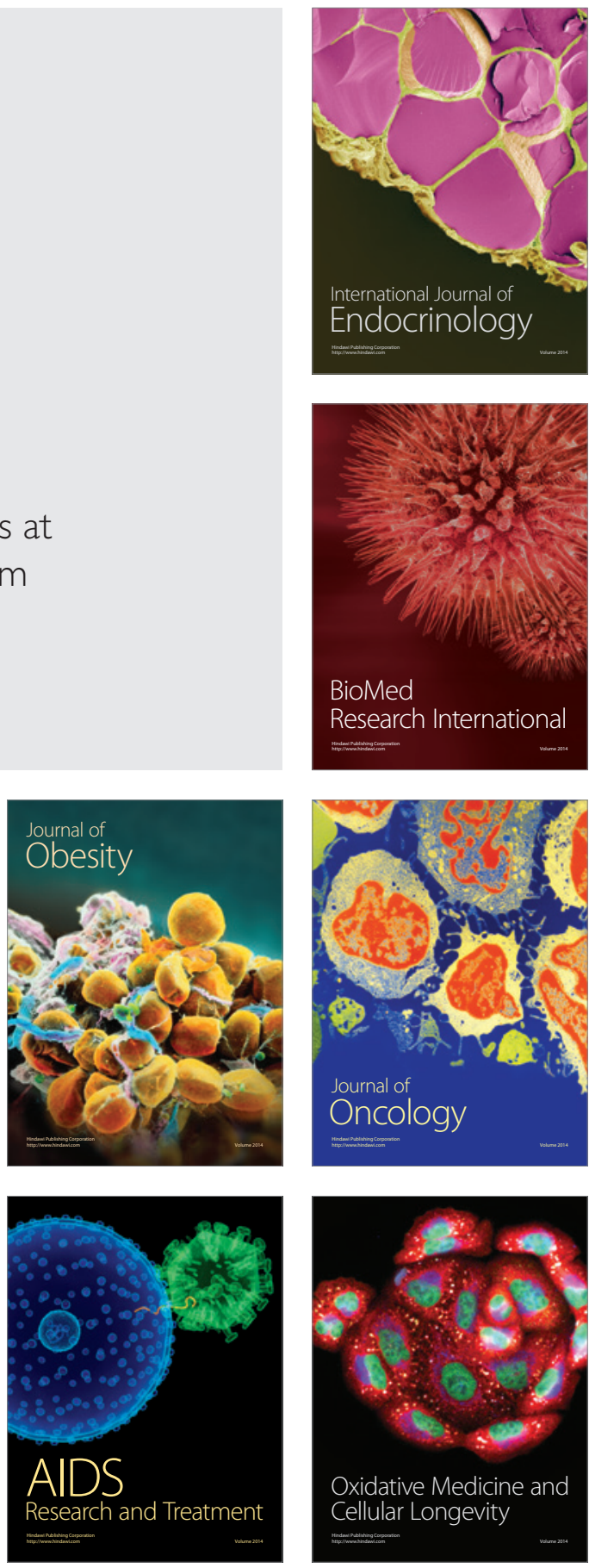